\title{
Negativity in a Twitter Age: How Politicians are Adapting to Social Media
} Mia Moody*, Liz Cohen and Claire Fournon

Journalism \& Media Arts, Baylor University, USA

\begin{abstract}
This study investigates negative campaigning and issue preferences as reflected in the use of Twitter posts released during the 2011-2012 presidential primaries. Negative political campaigning and policy-centered voting have become more prevalent in recent years, especially with the advent of the Internet and the subsequent increase in media sources such as blogs and social media platforms. Because voters use the Internet more than ever, it is important to study the types of material candidates disseminate to the public and the degree of negativity included in such content. Findings indicate that runner-up candidates were not more likely to use negativity in tweets in our sample.
\end{abstract}

\section{Introduction}

The Internet has transformed the election environment tremendously over the last decade. The medium provides relatively cheap opportunities for information dissemination and reception. Today's candidates use social media to give their viewpoints on events and to disseminate partisan appeals during election campaigns. The growth of social media from a fringe activity to a significant communication source illustrates an important change in gatekeeper functions. Previously, media conglomerates often dominated airwaves with status quo perceptions. New media, however, present a platform that levels the playing field, allowing politicians to disseminate information without a gatekeeper. Because voters often use this information to determine how they will vote, it is important to study the content candidates disseminate on their websites and the degree of negativity.

Scholars have examined negativity in presidential ads based on medium type and frequency for more than a decade [1-6]. However, despite the magnitude of studies on attack campaigning, little research exists on negativity in social media. To fill this void in the literature, this study provides an overview of the occurrence of negativity in content published in tweets during the 2011-12 presidential primaries.

\section{Twitter}

Using Twitter posts as the primary data source and content analysis as our method, we test the Grofman/Skaperdasmodel from a new vantage point-microblogging. The rise of social media as primary tools for communication has fostered the demise of the mediating role of traditional media between companies and publics. However, the viral environment cultivated in social media has raised major concerns. Statistics indicate many voters increasingly use the Web during election campaigns to gather information about a particular candidate as well as to sound off on key issues. For example, the 2011 Politics Online Report by Topix indicates that more than two-thirds ( 68 percent) of voters use the Internet as a primary source of information about candidates and political issues, second only to television (78 percent). Online news also ranked the most helpful political information source, with 89 percent of respondents calling it somewhat or extremely useful.

Findings may help shed light on how Republican candidates appealed to voters for their support through social media leading up to the 2011-2012 presidential primary races. The information gleaned from this article might also be useful for students, politicians, political scientists and public relations practitioners for decades to come, particularly as the gatekeeper-audience role in the political process continues to dramatically change.

\section{Literature Review}

\section{The history of negativity}

Wicks et al. [2] define negativity in campaigning as the process of going on the offensive against an opponent by presenting him or her in an unfavorable light. Negative campaigning often ignores issues and party agendas, and concentrates mainly on personality characteristics of opponents. In this case, a tweet is deemed negative if it has hostile, aggressive language or contains conflict. Negative campaigning may also be characterized by its ability to "impute inferiority, denigrate or destroy competitors' image".

According to Johnson-Cartee and Copeland [7], the use of negativity is older than television advertisements and takes its origins in what they called the "American tradition of negative campaigning." In the 1790's the country's newspapers were not independent but rather the voices of the political party that controlled them. "It was in these early newspapers that we see the beginnings of negative political campaigning. Indeed, from the earliest days of American republic, politicians engaged in personal attacks against their opponents that, as put it, were marked by their 'verbal excesses and emotional extravagances"' (p. 112). In addition to these partisan newspapers, politicians of the early American Republic used others kind of media to promote negativity such as songs, banners, torches, bandannas and billboards.

Moving to the $20^{\text {th }}$ Century, in 1952, Estes Kefauver discovered an early example of a negative television advertisement against the president, Dwight D. Eisenhower. This advertisement titled, "How's that again, general," contained two major elements often found in contemporary negative campaigns: chosen extracts of something the opponent said, along with proof or affirmation that he/she was wrong. The scheme behind this type of advertisement is to earn votes by showing the wrongs of an opponent.

*Corresponding author: Mia Moody, Assistant Professor, Journalism \& Media Arts, Baylor University, USA, Tel: 254-710-7247; E-mail: Mia_MoodyHall@baylor.edu

Received March 05, 2013; Accepted March 21, 2013; Published March 30, 2013

Citation: Moody M, Cohen L, Fournon C (2013) Negativity in a Twitter Age: How Politicians are Adapting to Social Media. J Mass Communicat Journalism 3: 151. doi:10.4172/2165-7912.1000151

Copyright: ( 2013 Moody M, et al. This is an open-access article distributed under the terms of the Creative Commons Attribution License, which permits unrestricted use, distribution, and reproduction in any medium, provided the original author and source are credited. 
Other articles have explored the landscape of negative advertisements or whether a candidate's ranking in the polls affects how voters perceive negative advertisements [8,9]. For instance, study findings suggest that the competitive position of candidates in a particular race is as a key antecedent of negative campaigning $[1,5,6]$. The model posits that frontrunners and rising challengers tend to receive more negative attacks than marginal or less competitive candidates because of their high approval rating or standing in the polls [3].

Moreover, the competitive competition thesis holds that candidates holding comfortable leads during campaigns tend to present positive content that promotes accomplishments and policy positions while trailing candidates tend to contrast their positions with those of frontrunners. In close races without a clear frontrunner, candidates tend to demonstrate significant attack behavior against opponents because each perceives that attacking an opponent through the media can be an effective way of attracting voters [2].

The competitive position model, as articulated by Grofman and Skaperdas [1], posits that negative campaigning is directed against the frontrunner and candidates lagging in the polls tend to engage in negative campaigning more frequently than frontrunners. Frontrunners, on the other hand, tend to refrain from such behavior unless attacked by an opponent. The model also suggests that in close races without a clear frontrunner, each candidate will tend to demonstrate significant attack behavior against opponents because each perceives that attacking an opponent through the media can be an effective way of attracting voters [2].

Krebs and Holian [10] found that although candidates attacked more frequently on salient than nonsalient issues, they were more likely to attack on character. The researchers reasoned this finding may reflect the nature of primary elections involving candidates with relatively similar issue positions; in this environment, character attacks may be more useful than issue attacks. Conversely, in runoff elections, attacks in the press were more likely to be about salient issues, whereas attacks in TV spots tended to be about character.

Similarly, Lovett and Shachar found that the tendency to turn to negative advertisements is higher in closer races (2011). These researchers observed that candidates who expect to lose are likely to resort to negative campaigning to slow the momentum of frontrunners. Attacks are more likely to occur as Election Day approaches, especially for a candidate running far behind. In another study, Chou \& Lien discovered that voters often support the candidate who is ahead in polls. Therefore, leading candidates are more capable of using negative advertisements to his or her advantage, because they have more support [9].

The 2012 Presidential Primaries provided the perfect stage to assess these models in a new media context. The race contained many heavy hitters in the Republican camp. For the purposes of this article, the researchers focused on following candidates, Mitt Romney, Rick Santorum, Ron Paul, Newt Gingrich, Rick Perry and Jon Huntsman. These six candidates stayed in the political race the longest and provided suitable content for this analysis.

\section{Online campaigning}

Traditionally, the public only had the opportunity to see candidates through two avenues: 1) made-for-publicity events such as interviews and 2) televised debates. Today, however, voters can interact via social media in which candidates disseminate their own messages. The
Internet has been a boon for politicians who often use multi-media websites to post news releases, radio transcripts, television ads, poll results and on-site campaign reports. Social media platforms such as Twitter feeds, Facebook posts and blogs are updated regularly, sometimes multiple times daily, giving voters the opportunity to provide and receive feedback in real time.

Trammell [11] asserts that self-presentation research takes on an interesting dimension when one looks at a virtual environment such as the Internet. One concern with self-publishing is candidates might disseminate information about other candidates with little or no regard for negativity. In the early years of the Internet, establishing a Web presence required skill and resources that prevented many people from publishing content; however, the arrival of interactive user-generated content (UGC) sites like YouTube has created an entirely new platform. The Internet is no longer a vehicle to retrieve information and to purchase goods; it is now a fully interactive, participatory platform driven by consumer-generated content.

A microblog is a type of blog that lets users publish short text updates. The posts are called micro posts, while the act of using these services to update a blog is called microblogging. Twitter, a form of microblogging, allows users to share posts that are up to 140 characters long. Having a message limited in length means that tweets have to be condensed information, often with links to websites, pictures or videos. While the number of active Twitter users is less than Facebook or e-mail, the concentration of highly engaged and influential content creators is unrivaled.

The difference that Twitter presents in relation to sports is its novelty in only allowing 140-characters at a time and having them accessible to millions of people in one location on a second-by-second basis. It also allows for a visual component since "twitpics" (photographs) can be instantly attached to any tweet that is posted. Twitter is one of the most publicized forms of online communication and is growing in popularity. It has between 15 and 18 million active users. That is a very large pool in which constituents can have instantaneous contact with, and a huge impact on, each other's perceptions and opinions

Additionally, as Twitter has increased in popularity, it has increasingly become a major source of information for journalists. Instead of tracking down a candidate's publicist or calling an agent for leads, they now simply sign onto Twitter. Both traditional newspaper and new media journalists, and even some television hosts, are turning to Twitter posts as a quick source of information on the latest buzz. If something catches their eye, they do a little follow up (usually online), maybe check the source, and then write an article, blog post, 60-second postgame television spot, etc., gleaned entirely from the 140-characters they read on Twitter. Rather than doing footwork and establishing newsworthy stories from trusted sources, journalists are increasingly turning to Twitter for topics with which to catch their audience's attention.

Candidate's use of online media during the presidential primaries provided a good opportunity for exploration of negativity within the realm of this relatively new medium. Existing media theories are the most efficient way to account for trends.

\section{Research Questions}

Based on a review of the literature, for research questionsguided this study of negative campaigning of candidates in the 2011-2012 presidential primaries. The were as follows: 
RQ1: What types of messages did candidates disseminate utilizing tweetsduring the 2001-12 Presidential Primaries?

RQ2: Were runner-up candidates more likely than front-runners to include a negative tone in their tweets?

RQ3: Were runner-up candidates more likely than front-runners to attack their opponents in their tweets?

RQ4: What interactive units did politicians use within their tweets. To what type of content did they link? What was the tone of candidate hashtags?

\section{Rationale}

To get a sense of how candidates utilized Twitter during the 201112 Presidential Primaries, the first and fourth research questions assessed themes and. These two questions also added context to our study findings.

The second and third research questionsare based on the competitive position model, which posits that candidates holding comfortable leads during campaigns. The model also suggests that in close races without a clear frontrunner, each candidate will tend to demonstrate significant attack behavior against opponents because each perceives that attacking an opponent through media can be an effective way of attracting voters. This study tests the model in a new media environment.

\section{Methods}

Using content analysis, the researchers looked at tweets posted from January 1, 2012 to June 5, 2012. January 1, 2012, marked the beginning of the peak campaign season. June 5 is the day when Mitt Romney officially won the Republican primary, which signifies the end of the race. The study included reading and identification of the key themes emphasized in the selected sample [12]. Researchers selected every other tweet for candidates for a total sample of 400 tweets.

To explore research question two, which asked if runner-up candidates are more likely than their opponents to have a negative tone in their tweets, and research question three, which asked if runnerup candidates are more likely than their opponents to discuss/attack their opponents' personal characteristics in their tweets, we compared the incidence of negative campaigning, as reflected in the tweets of Republican candidates. To answer research questions one and four, we examined the usage of links, as well as retweets, hashtags and mentions/ Twitter handles.

The unit of analysis for this study was the entire tweet. Section one looked at primary personal issues or topics and whether tweets discussed family, opinions, a call to action and a media appearance. Section two looked at the overall tone of the tweets. The choices were: "negative"-hostile, conflict or aggressive language used; "positive"optimistic, stressing fairness, logical and sensitive demeanor; and "neutral"-void of judgments, only statements of facts or reports of events. Finally, the third section addressed whether the tweet includes an attack aspect. Coders checked whether the tweets question another candidate's 1) truthfulness; 2) readiness for office; 3) behavior in the campaign; 4) strategies and tactics; 5) campaign conduct; 6) honesty and integrity; 7) includes a rebuttal to another person's attack; or 8) other.

A pilot study of 90 tweets helped refine the coding instrument. Nine graduate students identified categories and the best methods for identifying negativity in tweets. After refining themes for the codebook, two trained graduate students coded ten percent of the stories. The inter coder reliability was greater than 95 percent for negativity, 91 percent for attack and 75 percent for topics. Many tweets contained more than one topic, which resulted in a lower-than-expected inter coder reliability rating for topics. However, inter coder reliability for attack and negativity garnered a much higher rating, which allowed us to proceed with confidence that findings might provide valuable insight regarding negativity in the context of Twitter.

\section{Definitions}

Tweet: Describes a Twitter update using 140 characters or less. People tweet personal messages, random thoughts, post links, or anything else that fits in the character requirements (Beal, 2013).

Retweet: abbreviated as RT, Retweet is used on the Twitter Web site to indicate that the useris tweeting content that has been posted by another user. The format is RT @username where username is the twitter name of the person you are retweeting.

@reply or mention/Twitter handle: The @reply means a Twitter update (a tweet) that is directed to another user in reply to their update. An @reply will be saved in the user's "Replies" tab. Replies are sent either by clicking the 'reply' icon next to an update or typing @ username message (Beal, 2013). It is also known as a Twitter handle.

Hashtag (\#): is used to help sort a tweet in search engines.

Negative campaigning: A tweet is deemed negative if it has hostile, aggressive language or contains conflict. On the other hand, positive tweets contain optimistic language stressing fairness while presenting a logical and sensitive demeanor.

Tone of tweet: The tone of tweets assessed whether the tweet contained one of the following: 1) Negative-attack language, hostility, conflict or aggressive language; 2) Positive-optimistic, stressing fairness, announcing positive poll results; 3 ) Neutral-void of judgments, only statements of facts or reports of events.

Personal attacks: Personal attack tweets include those that question another candidate's truthfulness, or readiness for office, or address a candidate's behavior in the campaign, among other attributes.

\section{Candidate standings}

Frontrunners fluctuated throughout the 2011-2012 primary campaign season: however, Gov. Mitt Romney former, Governor of Massachusetts, remained a frontrunner throughout most of the campaign season (Figure 1). The primary contest began in 2011 with

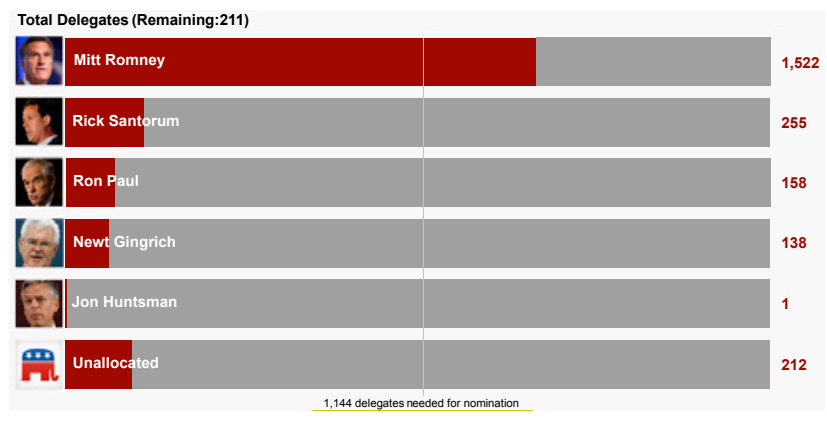

Figure 1: Republican candidates and positions in presidential primary elections in 2012

Source: Associated Press, Republican National Committee documents, POLITICO research 6/30/2012. 
Romney weighing in as likely to win the nomination. By February 2012, the following candidates were in the race: Former House speaker Newt Gingrich, U.S. Congressman Ron Paul, former Governor Romney and former U.S. Senator Rick Santorum.

Santorum concluded his campaign on April 10, a week after losing Wisconsin and two other primaries to Romney. Gingrich followed suit on May 2, after representatives at the Republican National Convention had declared Romney the presumptive nominee on April 25 and put its resources behind him. On May 29, Romney reached the nominating threshold of 1,144 delegates by most projected counts following his primary win in Texas [13].

\section{Findings}

Dominant themes: The first research question asked what types of messages did candidates disseminate utilizing tweets during the 200112 Presidential Primaries? Findings indicate that most tweets fell in the opinion category, meaning they expressed a candidate's opinion about a topic or issue. Out of his 100 tweets in our sample, Paul had the most in this category 77 (40\%), while Romney had the least 30 (15\%). Worth noting is many tweets in this category, expressed what the candidate would do if elected president. The call to action category was the next largest section with 42 of Gingrich's tweets falling in this category and 24 of Rick Santorum's.

"Announcement of a media appearance/campaign" stop made up the next largest category with 12 of Santorum's 100 tweets in our sample falling in this category and 11 of Gingrich's. The candidate's had fewer tweets in the "family" category than any other section. Romney had four while Santorum had three in this category (Table 1).

Call to action tweets encouraged constituents to take on stand on campaign platforms or to vote for a particular candidate. The included the following messages, "Vote for me," "exercise your right to vote," and "Donate to my campaign." Gingrich included the most tweets in this category, $42(47 \%)$ of his 100 tweets in our sample, followed by Romney and Santorum who included $19(21 \%)$ and $24(27 \%)$ respectively.

Twitter tone: The second research question asked, were runnerup candidates more likely than front-runners to include a negative tone in their tweets? Referring back to the literature, the competitive competition thesis holds that candidates holding comfortable leads during campaigns tend to present positive content that promotes accomplishments. Here the model does not hold true for the four politicians in our sample. Romney, the frontrunner, included 53 positive tweets while runner-up candidates; Santorum, Paul and Gingrich include 78, 78 and 89 of positive tweets respectively (Table 1).

Out of his 100 tweets, Romney included 45 negative ones (Figure 2). His Twitter content often criticized Obama while emphasizing how he would handle issues more effectively. The candidate also used Twitter for "soft news" such as thanking supporters, acknowledging endorsements and greeting friends. Santorum and Paul included

\begin{tabular}{|c|c|c|c|c|c|c|c|c|}
\hline \multirow[t]{2}{*}{ Candidate } & \multicolumn{2}{|c|}{ Family } & \multicolumn{2}{|c|}{ Opinion } & \multicolumn{2}{|c|}{$\begin{array}{l}\text { Call to } \\
\text { Action }\end{array}$} & \multicolumn{2}{|c|}{$\begin{array}{l}\text { Announcement of } \\
\text { media appearance }\end{array}$} \\
\hline & Freq & $\%$ & Freq. & $\%$ & Freq. & $\%$ & Freq. & $\%$ \\
\hline Mitt Romney & 4 & .40 & 30 & .15 & 19 & .21 & 5 & .15 \\
\hline Newt Gingrich & 2 & .20 & 39 & .20 & 42 & .47 & 11 & .32 \\
\hline Ron Paul & 1 & .10 & 77 & .40 & 4 & .05 & 6 & .18 \\
\hline Rick Santorum & 3 & .30 & 49 & .25 & 24 & .27 & 12 & .35 \\
\hline $\mathrm{n}$ & 10 & $100 \%$ & 195 & $100 \%$ & 89 & $100 \%$ & 34 & $100 \%$ \\
\hline
\end{tabular}

Table 1: Breakdown of topics in politicians' tweets.
त. Mitt Romney@MittRomney

Sign my petition telling @BarackObama to replace the Gas Hike Trio with leaders who support affordable energy mi.tt/FRSJ $8 p$

Mitt Romney@MittRomney

While we welcome a decline in unemployment, these numbers can't hide the fact that the Ptesident's policies have prevented a true recovery.

Mitt Romney @MittRomney
@RickSantorum knows he's losing GOP vote so he's inviting
Democrats to vote in the MI Primary. Fight back mi.tt/z6M6gs
\#pathetic

Mitt Romney @MittRomney

How many excuses can@BarackObama buy with \$2M? We need a President who is accountable onetermfund.com \#OneTermFund

Mitt Romney@MittRomney

America today has the highest business tax in the world and now @BarackObama wants a new global business tax. \#ObamaLogic

Figure 2: Mitt Romney's tweets during the 2011-12 Presidential Primaries.

\begin{tabular}{|l|c|c|c|}
\hline Name & Negative & Positive & Neutral \\
\hline Mitt Romney & 45 & 53 & 2 \\
\hline Rick Santorum & 12 & 78 & 10 \\
\hline Ron Paul & 14 & 76 & 10 \\
\hline Newt Gingrich & 8 & 89 & 3 \\
\hline $\mathrm{n}$ & 79 & 296 & 25 \\
\hline
\end{tabular}

Table 2: Tone of politician's tweets.

almost an equal number of negative tweets, 14 and 8 respectively. Gingrich had the least number of negative tweets (Table 2).

All four candidates were similar in their number of neutral tweets with each one including from 2 to 10 neutral tweets. Romney had the least number of neutral tweets (2) while Santorum and Paul tied with 10 neutral tweets a piece.

\section{Attack rhetoric}

The third research question asked, are runner-up candidates more likely than front-runners to attack their opponents in their tweets? Romney was the candidate most likely to include attack rhetoric than all three candidates (78\%). In fact, 38 of Romney's 100 tweets targeted President Obama and his administration. Four tweets targeted other Republican candidates. At least once a week, Romney's tweets discussed Obama's policies and how they are hurting the U.S. government. He also used his tweets as an opportunity to talk about religion, jobs and deployed troops. Romney also questioned the campaign conduct of Santorum, as well as his honesty and integrity.

Conversely, Paul used one of his tweets to attack the administration and 11 to attack Republican rivals. Paul's tweets included, "Why Ron Paul matters more than Obama, Romney, Santorum and Gingrich" and "I leave others "in the dust" in military donations." Paul also drew a lot of attention by twisting the words of his opponents to may himself look better. A video attached to a tweet stated, "Thanks Rick Santorum for telling voters that the only true conservative choice in this race is Ron Paul!” 
Illustrating a different stance, the majority of Gingrich's tweets centered on the campaign promise for "\#250gas, aggressive job creation and a $21^{\text {st }}$ century Contract w/America” (@NewtGingrich April 10, 2012 tweet) and "the fight to defeat Barack Obama" (@NewtGingrich, May 3, 2012 tweet). After Gingrich's withdrawal from the presidential race, he continued to tweet about removing Obama from the office. He responded to his constituents often and answered their questions. Occasionally he retweeted his wife, Callista, as the couple thanked their supporters and reflected on their visits to various campaign stops.

Worth noting, as evidenced from Table 2, the majority of tweets were not attacks at all. But of the ones that were attacks, usually a candidate used tweets to question another person's experience or to question his campaign's strategies and tactics. In rare instances, a candidate questioned another's candidate's conduct or his or her honesty and integrity Tables 3 and 4 .

\section{Interactive units used within politicians' tweets}

The final research question what interactive units did politicians use within their tweets? Links were found to be the most common of the units used within each tweet (Table 5). Ron Paul's Twitter content was the most likely to include links (87of 100 of his tweets included interactive elements). Similarly, 79 of NewtGingrich's 100 tweets in our sample included interactive elements. Paul also included the most hashtags in his Twitter content (91), followed by New Gingrich who had 49. Mitt Romney's Twitter content contained the most mentions or Twitter handles for himself and other candidates, 51 .

Paul was the only candidate who included interactive elements in all of his Twitter content. Conversely, Romney had the most content that had no interactive elements. Not surprisingly, 90 of Paul's Twitter content contained multiple interactive units. The candidate utilized links and hashtags together in the majority of his tweets Figure 3.

Gingrich used @mentions/Twitter handles to send a positive message to Rick Santorum sympathy when his daughter reentered the hospital (Illustration 3). He also used them to target President Obama with a message about weak job reports.

Twitter linkages: The second part of this question asked to what type of content did they link? Twitter's 140 characters can be restricting for a candidate who wants to pass a long message on to the public; therefore, they usually provide a link was used to go into more detail on a certain subject. Findings indicate that websites make up the majority of what a politician tends to send people to from their Twitter feed.
Each candidate linked to his website in more than 70 of their tweets with an interactive unit. For instance, Romney included a link to his website in 92 of interactive tweets.

Videos andpictures were less common (Table 6). Paul included the most pictures in his interactive tweets, 17, followed by Santorum with 13. Romney included pictures in five of his interactive units while Gingrich included pictures in almost 8 of his interactive units. Gingrich included more videos in his interactive units than any other candidate while Romney included the least, 3.

Negativity in interactive elements: The last section of research question four asked, what was the tone of candidate hashtags? Worth noting is candidates usually placed hashtags at the end of a tweet, often to punctuate or emphasize the content of their tweet. Most hashtags were either positive or neutral usually linking to the candidate's name or campaign platform.

According to Table 7, Romney was the only candidate that included tweets with a negative tone, 34. Most of these negative hashtags were aimed the Obama administration: examples included \#OneTermFund, \#ObamaFlexibility or \#StopTheSpending. Worth noting is Romney also included positive/neutral hashtags such as \#Mitt2012, \#JerseyComeback. His neutral hastags publicized events such as the debates, i.e. \#CNNdebates.

Paul's Twitter content included the most positive and neutral hashtags at 91. Most of his tweets included \#RonPaul2012 (Illustration 4). Gingrich included the next highest, 77. Gingrich's most popular hashtags were \#drillnow, \#withnewt, \#America. Conversely, most of Santorum's hashtags were neutral at 62 . Conversely, Romney and Gingrich included the same percentage of neutral hashtags, around 23 each. Santorum's most popular hashtags included \#jointhefight and \#TeamSantorum Figure 4.

\section{Discussion and Conclusions}

This study looked at negativity during the 2011-12 Republican Presidential Primaries. The Webenables politicians to bypass traditional gatekeepers. Likewise, voters access such information without a gatekeeper such as an editor or reporter to provide fair and balanced reporting. Consequently, the gatekeeper-audience dynamic has changed with the popularity of personal publishing

Findings indicate attack and negative rhetoric was more common in the tweets of the frontrunner candidate. This conclusion differs

\begin{tabular}{|l|c|c|c|c|c|c|c|}
\hline \multirow{2}{*}{ Candidate } & \multicolumn{2}{|c|}{ Attacks Obama/Administration } & Attacks Candidate within Party & \multicolumn{3}{|c|}{ Attacks Candidate outside Party } & \multicolumn{2}{c|}{ Endorses another candidate } \\
\cline { 2 - 7 } & Freq. & $\%$ & Freq. & $\%$ & Freq. & Freq. \\
\hline Mitt Romney & 38 & .78 & 4 & .18 & 0 & 0 \\
\hline Rick Santorum & 5 & .10 & 7 & .30 & 0 & 0 \\
\hline Ron Paul & 1 & .02 & 11 & .48 & 0 & 0 \\
\hline Newt Gingrich & 5 & .10 & 1 & .04 & 0 & 0 \\
\hline $\mathrm{n}$ & 49 & $100 \%$ & 23 & $100 \%$ & 0 & 0 \\
\hline
\end{tabular}

Table 3: Attack attributes included in politician's tweets

\begin{tabular}{|c|c|c|c|c|c|c|c|c|c|c|c|c|}
\hline \multirow{2}{*}{\begin{tabular}{|l} 
Name \\
Mitt Romney \\
\end{tabular}} & \multicolumn{2}{|c|}{ Rebuttal } & \multicolumn{2}{|c|}{ Rebuttal } & \multicolumn{2}{|c|}{$\begin{array}{c}\text { Question Strategies and } \\
\text { Tactics }\end{array}$} & \multicolumn{2}{|c|}{$\begin{array}{l}\text { Question Campaign } \\
\text { Conduct }\end{array}$} & \multicolumn{2}{|c|}{$\begin{array}{l}\text { Question Honesty } \\
\text { and Integrity }\end{array}$} & \multicolumn{2}{|c|}{ No Attack } \\
\hline & 29 & .54 & 0 & 0 & 8 & .53 & 1 & .50 & 4 & 1 & 58 & .18 \\
\hline Rick Santorum & 11 & .20 & 0 & 0 & 1 & .07 & 0 & 0 & 0 & 0 & 88 & .27 \\
\hline Ron Paul & 10 & .19 & 0 & 0 & 3 & .20 & 1 & .50 & 0 & 0 & 86 & .26 \\
\hline Newt Gingrich & 4 & .07 & 0 & 0 & 3 & .20 & 0 & 0 & 0 & 0 & 93 & .29 \\
\hline$n$ & 54 & $100 \%$ & 0 & 0 & 15 & $100 \%$ & 2 & $100 \%$ & 4 & $100 \%$ & 325 & $100 \%$ \\
\hline
\end{tabular}

Table 4: Attack attributes included in politician's tweets. 
Citation: Moody M, Cohen L, Fournon C (2013) Negativity in a Twitter Age: How Politicians are Adapting to Social Media. J Mass Communicat Journalism 3: 151. doi:10.4172/2165-7912.1000151

\begin{tabular}{|l|c|c|c|c|c|c|}
\hline Name & Links & $\begin{array}{c}\text { Hashtags } \\
\text { (\#) }\end{array}$ & Retweets & $\begin{array}{c}\text { Mentions/ } \\
\text { Twitter handle } \\
(@)\end{array}$ & None & Multiple \\
\hline Rick Santorum & 64 & 37 & 4 & 25 & 14 & 37 \\
\hline Ron Paul & 87 & 91 & 9 & 14 & 0 & 90 \\
\hline Mitt Romney & 60 & 34 & 2 & 51 & 18 & 47 \\
\hline Newt Gingrich & 79 & 49 & 4 & 26 & 5 & 53 \\
\hline $\mathrm{n}$ & 290 & 211 & 19 & 116 & 37 & 227 \\
\hline
\end{tabular}

Table 5: Interactive units used within politicians' tweets.

Newt Gingrich@newtgingrich

@CallyGingrich and I have@RickSantorum and family in our prayers since their daughter bella is back in the hospital

Newt Gingrich

Another month, another weak jobs report under@BarackObama. November is coming. \#tcot

Newt Gingrich

We want to hear from you campaign \& bold ideas. newt.org/submit-your-vi... \#withNewt

Figure 3: Newt Gingrich's Twitter Presence.

\begin{tabular}{|l|c|c|c|}
\hline Name & Video & Picture & Website \\
\hline Rick Santorum & 13 & 13 & 75 \\
\hline Ron Paul & 8 & 17 & 75 \\
\hline Mitt Romney & 3 & 5 & 92 \\
\hline Newt Gingrich & 22 & 8 & 71 \\
\hline $\mathrm{n}$ & 46 & 43 & 313 \\
\hline
\end{tabular}

Table 6: Breakdown of what tweets link to.

\begin{tabular}{|l|c|c|c|}
\hline Name & Negative & Positive & Neutral \\
\hline Rick Santorum & 0 & 38 & 62 \\
\hline Ron Paul & 0 & 91 & 9 \\
\hline Mitt Romney & 34 & 43 & 23 \\
\hline Newt Gingrich & 0 & 77 & 24 \\
\hline $\mathrm{n}$ & 34 & 249 & 118 \\
\hline
\end{tabular}

Table 7: Tone of hashtags used by politicians.

fromprevious studies, which showed that frontrunners are less likely to use negativity or attack language. Findings offered several facets to explore. Since the Democrats already had their nominee, President Barack Obama, candidates attacked him during the presidential primaries regardless of their place in the political race. Romney, who went on to win the Republican nomination, attacked President Obama throughout the primaries. On the other hand, candidates such as Santorum and Paul, who attacked a Republican more often than the current administration, were doing so because fellow Republicans who were their closest rivals.

Also worth noting is politicians in this sample used Twitter for more than attacking one another. They tweeted about family, their personal opinions on important matters, as well as announced media appearances and called on the public to take action and become involved in political matters. The researchers were surprised that the majority of tweets are positive in nature. However, after considering the nature of Twitter, it made more sense. Tweets are meant to be quick, personal messages, conversation starters. Therefore, candidates used them to interest potential voters in their political platform.

A follow-up study might look at whether tweets influenced the types of stories published in newspapers or network news. Such a
Ron Paul @RonPau

New Post: Why Ron Paul matters more than Obama, Romney, Santorum and Gingrich ow.ly/ablz5 \#gop2012 \#tcot \#RonPaul

RonPaul@RonPau out here: ow.ly/a8puk \#tcot \#gop2012 \#RonPaul

Ron Paul @RonPau \#RonPaul

RonPaul@RonPaul

I'm making a three-day campaign visit to California starting tomorrow.

Details here: ow.ly/a1OAO \#CAgop \#gop2012 \#tcot \#RonPaul

Ron Paul @RonPaul "I'm trying to save the Republican Party from themselves" ow.ly/a1qBt \#gop2012 \#tcot \#RonPaul

Ron Paul @RonPau

Ron Paul rocks Wisconsin! [Photo] ow.ly/9YUg1 \#RonPaul \#tcot \#gop2012

RonPaul@RonPaul

My statement on the House passage of the Paul Ryan budget: ow.ly/9YOKn \#tcot \#gop2012 \#RonPaul

Figure 4: Ron Paul's Twitter Presence.

study might also be paired with an agenda-setting study to find out how consumers used such information to make their decisions on what to publish. Another way to add to the literature is to compare when attacks occurred over tweets or advertisements, to poll data at about the same time. An assessment of why candidates attack would open up more facets of discussion in the field of negativity in social media.

Study findings are particularly relevant given the tremendous popularity of the Web. Some observers predict user generated content (UGC) such as YouTube videos, websites, blogs and other forms of mass media may eventually displace traditional broadcast media as the main outlet for news and entertainment. Politicians are their own gatekeepers in social media, and thus they can discuss whatever they like on their Twitter feed. Tweets are free, highly visible and effective if they are used tactfully.

\section{References}

1. Grofman B, Skaperdas S (1995) Modeling negative campaigning. The American Political Science Review 89: 49-61.

2. Verser, Wicks RH (2006) Managing Voter Impressions: The Use of Images on Presidential Candidate Web Sites During the 2000 Campaign. Journal of Communication 56: 178-197.

3. Haynes A, Rhine S (1998) Attack politics in presidential nomination campaigns: An examination of the frequency and determinants of intermediated negative messages. Political Research Quarterly 51: 691-721.

4. Damore D (2002) Candidate strategy and the decision to go negative. Political Research Quarterly 55: 669-685.

5. Buell E, Sigelman L (2003) You take the high road and I'll take the low road? The interplay of attack strategies and tactics in presidential campaigns. The Journal of Politics 65: 518-531.

6. Djupe P, Peterson D (2002) The impact of negative campaigning: Evidence from the 1998 senatorial primaries. Political Research Quarterly 55: 845-860.

7. Johnson-Cartee K, Copeland G (1991) Negative Political Advertising: Coming of Age.

8. Lovejoy J, Riffe D, Cheng H (2012) Campaign Interest and Issue Knowledge: 
Citation: Moody M, Cohen L, Fournon C (2013) Negativity in a Twitter Age: How Politicians are Adapting to Social Media. J Mass Communicat Journalism 3: 151. doi:10.4172/2165-7912.1000151

Page 7 of 7

Did the Media-and Negative Political Advertising-Matter in "Battleground Ohio"? From The Atlantic Journal of Communication.

9. Chou H, Lien N (2010) How do candidate poll ranking and election status affect the effects of negative political advertising? From The International Journal of Advertising.

10. Krebs T, Holian D (2007) Competitive positioning, deracialization, and attack speech preview. American Politics Research 35: 123-149.
11. Trammell K, Williams A Postelnicu M, Landreville K (2006) Evolution of Online Campaigning: Increasing Interactivity in Candidate Web Sites and Blogs Through Text and Technical Features. Mass Communication \& Society Winter 9: 21-44.

12. Entman R (1991) Framing U.S. coverage of international news: contrasts in narratives of the KAL and Iran air incidents. Journal of Communication 41: 6-27.

13. Romney clinches GOP nomination with Texas primary win (2012) Fox News 